\title{
La responsabilidad médica frente a la reforma del Código de Procedimiento Civil y del Código Contencioso Administrativo*
}

\author{
Juan Manuel Herrera Jiménez* \\ Recibido: 30 de agosto de 2016 • Aprobado: 5 de octubre de 2016
}

\section{Resumen}

La reforma presentada al Código de Procedimiento Civil y al Código Contencioso Administrativo por parte del legislador en cuanto al tema de la valoración de la prueba y la oralidad, en lo que concierne específicamente a la responsabilidad médica, permite hablar de un nuevo cambio al adecuar esta a la Constitución de 1991, prevaleciendo el derecho sustancial y la aplicación a los principios de la eficacia, el debido proceso, la celeridad y la igualdad. Este último punto se estudia en el presente artículo con el objetivo de determinar si se da el equilibrio procesal entre las partes, sin que se presenten vacíos que en un momento específico favorecezcan de manera errónea a alguna de ellas. Por ello, al introducirse el proceso oral y por audiencias, así como el aporte de pruebas en el tema de responsabilidad médica, se tiene en cuenta que la norma señala que la carga dinámica de la prueba se encuentra en la figura a quien le atañe probar una verdad o afirmación y que, llegado el caso, se decretarán pruebas de oficio de acuerdo con la manera como lo determina ley, para lograr la igualdad entre las partes.

"El presente artículo es producto del proyecto de investigación "Responsabilidad médica frente a la reforma del Código de Procedimiento Civil y al Código Contencioso Administrativo", el cual fue gestionado en la Universidad Sergio Arboleda como condición para optar al título de magíster en derecho. DOI: http://dx.doi.org/10.15332/s1900-0448.2017.0046.04

" Magíster en Derecho de la Universidad Sergio Arboleda. Docente de la Universidad Gran Colombia. Correo electrónico: juanmherreraj24@yahoo.es 
Este artículo se centra en los cambios dados a la norma en lo que respecta a la valoración de la prueba y la oralidad en la responsabilidad médica ${ }^{1}$. Para ello se parte del análisis de la ley, la jurisprudencia y la doctrina para así llegar a una síntesis explicativa que nos indicará si con la oralidad y la valoración de la prueba introducida en la reforma del Código de Procedimiento Civil puede verse afectado el debido proceso, señalado en el artículo 29 de la Constitución de 1991, disposición que fundamenta los cambios jurídicos que en el ámbito procesal se han venido dando 2 . Los resultados indican que en su distribución legal con la implementación de la oralidad, la prueba permite que las partes alleguen documentos, bien sea de los provenientes de los funcionarios como de los particulares de acuerdo con sus funciones o intervenciones. Siendo de gran importancia entre las pruebas documentales la historia clínica y la pericial, que es la innovación que trae la reforma legislativa, así como la objeción mediante interrogatorio a un auxiliar de la justicia para que acredite la fuente científica de la prueba, permite con ello la admisión y valoración, en aras de un correcto entendimiento que facilite dar un fallo objetivo por parte del juez, sin que se llegue a ver afectado el debido proceso, el que ha venido siendo protegido por medio de la jurisprudencia emitida por las Altas Cortes y los tratados internacionales ratificados por Colombia, que forman parte del bloque de constitucionalidad.

Palabras clave: Responsabilidad médica, carga de la prueba, carga dinámica de la prueba, debido proceso, fallo objetivo, jurisprudencia, ley.

${ }^{1}$ De conformidad con el maestro Echeverri Uruburu (2011), es necesario anotar lo siguiente en razón a que está en contexto con la temática del presente manuscrito: "Cada cierto tiempo se coloca en la agenda de los grandes problemas nacionales el tema de la necesidad de la reforma a la justicia, lo cual no deja de resultar paradójico si se tiene en cuenta que la administración de justicia en Colombia ha sufrido la más grande reforma en su aparato en virtud de la Constitución de 1991, sin duda, la más profunda que se haya realizado en América Latina en los últimos veinte años". (Echeverri, 2011, p.45).

${ }^{2} \mathrm{Al}$ respecto, es importante hacer referencia a González (2014), quien considera que "La inactividad o silencio de los órganos legislativos del Estado colombiano, frente a un mandato constitucional, conlleva desconocimiento de principios, constituciones, valores y derechos de los administrados y, por ende, genera consecuencias jurídicas. En este sentido, ante el vacío normativo producido por la comisión legislativa absoluta o total, le corresponde al máximo órgano constitucional, como agente del campo jurídico, ejercer su capacidad de imponer con fuerza de autoridad sus pronunciamientos, crear una regla jurídica y aplicar en forma directa criterios axiológicos de la Carta Política, subsanando con ello la inactividad del legislador". (González, 2014, p.123). 


\title{
Medical liability in the Reform of the Code of Civil Procedure And the Contentious Administrative Code
}

\begin{abstract}
The reform presented to the Code of Civil Procedure and the Contentious Administrative Code by the legislator on the subject of assessment of the evidence and orality, in what concerns specifically to medical liability, allows to speak of a new change in adapting this to the Constitution of 1991, prevailing substantive law and the application of the principles of efficacy, due process, celerity and equality. This last point is studied in this article with the purpose of determining if there is procedural equality between the parties, without the existence of gaps that in a specific moment may favor one of them erroneously. Therefore, when introducing the oral process and in hearings, as well as the submitting of evidence in the topic of medical liability, it is taken into account that the standard indicates that the dynamic burden of proof falls on the person who has to prove a truth or assertion and that, as the case may be, the judge may order evidence by his own initiative will be ordered in the form determined by law, in order to achieve equality between the parties.

This article focuses on the changes to the standard concerning the assessment of evidence and orality in medical liability ${ }^{3}$. To do so, it is based on the analysis of the law, jurisprudence and doctrine, in order to arrive to an explanatory summary that will indicate whether the oral procedure and the assessment of the evidence introduced in the reform of the Code of Civil Procedure may affect the due process, stipulated in article 29 of the Constitution of 1991, provision based on which the legal changes in the procedural sphere have been made ${ }^{4}$.
\end{abstract}

\footnotetext{
${ }^{3}$ According to professor Echeverri Uruburu (2011), it is necessary to note the following since it is in context with the topic of this paper: "From time to time the topic of the necessity of the reform to justice is put in the agenda of the major national issues, which is paradoxical if you take into account that the administration of justice in Colombia has undergone the greatest reform in its system under the Constitution of 1991, undoubtedly the most profound that has been performed in Latin America in the last twenty years". (Echeverri, 2011, p.45).

${ }^{4}$ In this regard, it is important to refer to González (2014), who considers that "The inactivity or silence of the legislative organs of the Colombian State, with regards to a constitutional order, entails disregarding principles, constitutions, values and rights of the citizens and, hence, generates legal consequences. In this sense, given the legislative gap produced by the absolute or total legislative commission, it is up to the highest constitutional body, as an agent of the legal field, to exercise its capacity to impose with force of authority its pronouncements, to create a legal rule and to directly apply axiological criteria of the Political Constitution, thereby remedying the legislator's inactivity". (Gonzalez, 2014, p. 123).
} 
The results indicate that in its legal distribution with the implementation of orality, the evidence allows the parties to produce documents, either from officials or from individuals according to their functions or participation. Being of great importance among the documentary evidence the clinical history and the expert opinion, which is the innovation of the legislative reform, as well as the objection through questioning to an assistant of the justice to demonstrate the scientific source of the evidence. This allows the admission and assessment for the sake of a correct understanding that facilitates issuing an impartial judgment by the court, without affecting the due process, protected through the jurisprudence of the High Courts and the international treaties ratified by Colombia, which form part of the constitutionality block.

Keywords: Medical liability, burden of proof, dynamic burden of proof, due process, impartial judgment, jurisprudence, law.

\section{A responsabilidade médica perante a reforma do Código de Processo Civil e do Código Contencioso Administrativo}

\section{Resumo}

A reforma apresentada ao Código de Processo Civil e a Código Contencioso Administrativo por parte do legislador no relacionado com o tema da valoração da prova e a oralidade, no que concerne especificamente a responsabilidade médica, permite falar de uma nova mudança ao adequar esta a Constituição de 1991, prevalecendo o direito substancial e a aplicação dos princípios da eficácia, o devido processo, a celeridade e a igualdade. Este último ponto se estuda no presente artigo com o objetivo de estabelecer se ocorre o equilíbrio processual entre as partes, sem que se apresentem vazios que em um momento especifico favoreçam de forma equivocada alguma delas. Por isso, ao se introduzir o processo oral e por audiências, assim como o aporte de provas no tema da responsabilidade médica, se leva em consideração que a norma assinala que a carga dinâmica da prova se encontra a figura de quem deve provar uma verdade ou afirmação e que, dado o caso, se decretarão prova de oficio de acordo com a maneira como o estabelece a lei para lograr a igualdade entre as partes. 
Este artigo se foca nas mudanças acontecidas na norma no relacionado com a valoração da prova e a oralidade na responsabilidade médica ${ }^{5}$. Para isso parte-se da análise da lei, a jurisprudência e a doutrina para assim ter uma síntese explicativa que nos indicará se com a oralidade e a valoração da prova introduzida na reforma ao Código de Procedimento Civil pode afetar o devido processo, assinalado no artigo 29 da Constituição de 1991, disposição que fundamenta as mudanças jurídicas que no âmbito processual tem acontecido ${ }^{6}$.

Os resultados indicam que na sua distribuição legal com a implementação da oralidade, a prova permite que as partes reúnam documentos, seja provenientes dos funcionários como dos particulares de acordo com suas funções ou intervenções. Sendo de grande importância entre as provas documentais a história clínica e a pericial, que é a inovação que traz a reforma legislativa, assim como a objeção mediante interrogatório a um auxiliar da justiça para que acredite a fonte cientifica da prova, permite com isso a admissão e valoração, em favor de um adequado entendimento que facilite emitir uma sentença objetiva por parte do juiz, sem que se afete o devido processo, o qual tem sido protegido por meio da jurisprudência emitida pelas Altas Cortes e os tratados internacionais ratificados pela Colômbia, que formam parte do bloco de constitucionalidade.

Palavras-chave: Responsabilidade médica, carga da prova, carga dinâmica da prova, devido processo, sentença objetiva, jurisprudência, lei.

${ }^{5}$ De acordo com o mestre Echeverri Uruburu (2011), é preciso levar em consideração o seguinte porque faz parte do contexto da temática de este manuscrito: "Eventualmente se coloca na agenda dos grandes problemas nacionais o tema da necessidade da reforma à justiça, o qual não deixa ser um paradoxo ao levar em consideração que a administração de justiça na Colômbia tem sofrido a maior reforma em seu sistema em virtude da Constituição de 1991, sem dúvida, a mais profunda que se tem realizado na América Latina nos últimos vinte anos”. (Echeverri, 2011, p.45)

${ }^{6}$ Ao respeito, é importante fazer referencia a González (2014), que considera: "A inatividade ou silêncio dos órgãos legislativos do Estado colombiano, frente a um mandado constitucional, acarreta desconhecimento de princípios, constituições, valores e direitos dos administrados e, portanto, gera consequências jurídicas. Neste sentido, ante o vazio normativo produzido pela comissão legislativa absoluta ou total, corresponde-lhe ao máximo órgão constitucional, como agente do campo jurídico, exercer sua capacidade de impor com força de autoridade seus pronunciamentos, criar uma regra jurídica e aplicar em forma direta critérios axiológicos da Carta Política, corrigindo com isso a inatividade do legislador”. (González, 2014, p.123) 


\section{Introducción}

Desde la reforma de la norma, se han presentado pronunciamientos sobre el tema, principalmente en lo referente a la etapa probatoria, entre los que se tiene a juristas como Namén (2011) formó parte de la reforma al Código Contencioso Administrativo como secretario técnico ad hoc y señaló que la "reforma partió desde el nuevo esquema constitucional con el fin de fortalecer el régimen de pruebas con la utilización de las nuevas tecnologías y armonizar el esquema mixto (oralidad y escritura) con el objetivo de regular el régimen probatorio" (p. 1).

A su vez, Bejarano (2012), director del Departamento de Derecho Procesal de la Universidad Externado de Colombia, en el blog del ámbito jurídico expresa:

En materia de la prueba pericial, el propósito general del Código General del Proceso (CGP) es el de trasladar a las partes la responsabilidad de acompañar la experticia a la demanda o a la contestación, cuando pretenda probar hechos que requieran conocimientos de los que carezca el juez.

Por su parte, el jurista Rojas (2015) señala:

La carga de la prueba se traduce en la dificultad que tiene el paciente de corresponder a la demostración de la culpa o del nexo de casualidad que se da en una relación médico-paciente [...] se concluye que la carga de la prueba debe ser ajustada a la realidad del caso, es decir, que se debe romper con los moldes prefijados de pruebas para permitir la ágil hermenéutica del fallador, porque el juez no es un aplicador silencioso de la norma, es un creador de valores sociales, de reglas de convivencia y garante de derechos (p. 82).

El maestro Parra Quijano (2011) dice:

${ }^{7}$ Magistrado Auxiliar de la Sección Tercera del Consejo de Estado. Secretario técnico ad hoc (2010-2011) de la Comisión de Reforma al Nuevo Código de Procedimiento Administrativo y de lo Contencioso Administrativo, Bogotá (2011). 
[...] tener en cuenta la realidad de las partes, lo cual se logra con el interrogatorio exhaustivo de aquellas sobre el objeto del proceso, y poder distribuir, por ejemplo, la carga de la prueba, para evitar utilizar el sucedáneo de la prueba, caso en el cual la sentencia se podría obtener sustentada en la verdad real (p. 19).

De igual forma, el artículo 3. ${ }^{\circ}$ del CGP determina que "las actuaciones se cumplirán en forma oral, pública y en audiencias, salvo las que expresamente se autorice realizar por escrito o estén amparadas por reserva”. El artículo 6. ordena que el juez "deberá practicar personalmente todas las pruebas y las demás actuaciones judiciales que le correspondan” y programará, de acuerdo con el artículo 5. ${ }^{\circ}$, las "audiencias y diligencias, de manera que el objeto de cada una de ellas se cumpla sin solución de continuidad".

Los cambios dados en la norma y la importancia que se le da al proceso para efectos de la eficacia, celeridad, protección y conservación de las garantías al debido proceso establecido en la Constitución Nacional darán como resultado final beneficios para las partes de acuerdo con las pruebas aportadas al litigio, logrando con ello una sentencia justa en un tiempo razonable.

El objetivo del presente trabajo es determinar si se presentarán vacíos con los cambios dados por el legislador al introducir el proceso oral y por audiencias y el aporte de las pruebas en lo que se refiere a temas de responsabilidad médica. En este aspecto, se tiene en cuenta que la norma señala que la carga dinámica de la prueba se encuentra en la figura a quien le atañe probar una verdad o afirmación, y que, llegado el caso, el juez decretará pruebas de oficio de acuerdo con la manera como lo determina la ley para lograr la igualdad entre las partes ${ }^{8}$.

No se trata solo de determinar la responsabilidad médica por medio de la prueba, sino de evidenciar la vulneración de un derecho debidamente señalado en la Constitución de 1991 como derecho fundamental (como lo es el derecho a la vida); a su vez, del derecho a la salud, consagrado en el artículo 49, el que a partir de la sentencia T-760 de 2008 (Corte Constitucional, 2008) se considera un derecho fundamental en virtud del cual el Estado debe proteger a todos los ciudadanos que

${ }^{8}$ Para el efecto, Quintero ha propuesto lo siguiente: "No solamente la búsqueda de descongestionar la administración de justicia fue el motor de la creación del Código General del Proceso. La sociedad avanza al ritmo de sus necesidades, por las cuales abarcan aspectos económicos, sociales, culturales y, cómo no, tecnológicos, de esta manera se debe comprender que el derecho no es estático y que debe dar pasos agigantados para no quedarse atrás de los cambios sociales, por ende, debe avanzar al ritmo que la humanidad exija”. (Quintero, 2015, p. 101). 
se encuentren en Colombia y permitir el acceso a los servicios de seguridad social, sin importar su condición económica o social, hasta el punto de sobreponerlo a aspectos del orden financiero y de sostenibilidad del Sistema General de Seguridad Social en Salud.

\section{Metodología}

Para desarrollar el presente artículo, se partió desde dos perspectivas: la analítica, con relación a la normatividad, la jurisprudencia y la doctrina. De otra parte, en lo referente a la prueba pericial, la carga dinámica de la prueba y la oralidad se abordan desde el punto de vista jurídico, situándolas dentro del contenido del juicio de autoridad por parte del juez y conectándolas con una exigencia de justicia en relación con los sujetos implicados. De esta manera, se trata de llegar a una síntesis de tipo explicativo que nos señale la responsabilidad médica frente a la reforma del Código de Procedimiento Civil y el Código Contencioso Administrativo y que determine la objetividad e imparcialidad del juez en el análisis de la prueba y a quien le compete su carga.

\section{Resultado}

Como resultado del desarrollo del presente trabajo, se pudo establecer que los cambios dados al Código de Procedimiento Civil y al Código Contencioso Administrativo, de acuerdo con la importancia que se le da al proceso, nos permiten determinar que la prueba pericial, la carga dinámica de la prueba y la oralidad señalan el camino que se debe seguir para determinar la responsabilidad médica ${ }^{9}$ ante un hecho que vulnera un derecho fundamental de un ciudadano, como lo es la salud, tal como lo señaló la Corte Constitucional en su sentencia hito T-760 de 2008 (Corte Constitucional, 2008), en la que reitera que "el derecho a la salud es fundamental". Sin embargo, como cualquier derecho fundamental, la salud tiene

\footnotetext{
${ }^{9}$ De conformidad con Correa: "Cuando se habla de información de los pacientes, necesariamente nos remitimos al derecho médico, a la asistencia en salud y a los derechos y obligaciones que se involucran en la relación médico-paciente, que junto a toda una serie de características implícitas, hacen del tema un asunto de mayor complejidad al inicial acercamiento que pretenda quien quiera conocer sobre los derechos de confidencialidad, intimidad, reserva e inclusive la relación de la protección de datos y el derecho sanitario" (Correa, 2015, p. 125)
} 
un núcleo esencial que debe ser garantizado a todas las personas y que comprende, entre otros, "el derecho a acceder a servicios de salud de manera oportuna, eficaz y con calidad."

Dado el carácter de fundamental del derecho a la salud y la consecuente garantía en la prestación de servicios de salud, el legislador introdujo esos cambios en la normatividad que se analiza, con el fin de que las pruebas sean allegadas al proceso en su momento y permitan claridad para determinar con certeza la existencia de una responsabilidad en la prestación de un servicio.

Debe reiterarse que, aunque la prestación del servicio de salud se encuentra a cargo del Estado, este puede apoyarse en entes del sector privado, lo que implica al depender de la calidad del sujeto que brinde el servicio, la competencia se modifica en caso de presentarse fallas en la prestación del servicio, encontrando de una parte la jurisdicción civil (en caso de fallas por parte de entidades particulares) y la jurisdicción contencioso-administrativa (cuando involucra a sujetos de derecho público.)

\section{La oralidad en los procesos de responsabilidad médica}

Una de las principales virtudes de la oralidad es que otorga sentencias en un tiempo razonable, siendo una de las razones por las cuales el legislador ha incorporado el proceso oral y por audiencias, dando así aplicación a principios tales como a) la rapidez en el desarrollo del proceso (celeridad); b) la comunicación directa entre el juez y las partes (inmediación), es decir, un contacto directo y simultáneo de los sujetos procesales con los medios de prueba en que debe basarse la discusión plena de las partes y la decisión definitiva del juzgador; y c) el desarrollo ininterrumpido del proceso (concentración), sin dejar del todo el proceso escrito. La oralidad y la escritura coexisten para ser complementarias y no absolutas, y con ello se pretende abandonar la lentitud en los diferentes trámites y la demora en la resolución de la decisión por parte del juez.

El juicio oral y público reconoce la actuación efectiva de los intereses individuales y sociales que el proceso debe tutelar, a su vez, asegura una justicia más eficaz, carente de obstáculos y, sobre todo, que fortalece la confianza de los colombianos y la percepción social general, resultando ser más garantista.

Dado que la oralidad se refiere a los principios de inmediación, celeridad, concentración y economía del proceso, como lo indica la Corte en la sentencia C-591 de 2005 (Corte Constitucional, 2005, p. 46), que al referirse al principio 
de la inmediación trae a colación la definición de Pfeiffer para determinar que es aquella posibilidad "que tiene el juez de conocimiento de percibir directamente la práctica de pruebas para tomar la decisión acertada en el campo de la responsabilidad penal", se deduce que la inmediación es el procedimiento que durante la etapa de la oralidad se produce en la práctica de las pruebas ante el juez, haciéndose más rigurosa la presencia de este en las diferentes audiencias, por lo que debe asistir personalmente al desarrollo y a la evacuación de las pruebas, por cuanto de ellas deriva su convencimiento para poder pronunciarse en la sentencia; es decir, tiene el juez la obligación de entrar en relación directa con las partes, los testigos, los peritos y con los objetos del juicio, etc., apreciar sus declaraciones y las condiciones de las personas, los sitios y las cosas, para darse una inmediata impresión de ellos a fin de descubrir la verdad, que es la base de la justicia. Se busca una coincidencia entre la verdad real y la verdad procesal.

Durante ese proceso se inicia una polémica en la audiencia entre las partes y ante el juez, quien debe orientar esos intereses a una igualdad jurídica en la cual la libre discusión y el examen bilateral de todos los actos que realiza se fundamentan en el principio de contradicción, favoreciendo al mismo tiempo el descubrimiento de la verdad. Por eso, sin lugar a dudas, la oralidad genera mejores resultados que el escrito, pues se da una verdadera aplicación del principio de la inmediación.

$\mathrm{El}$ acogimiento de un proceso bajo un sistema mixto poderosamente marcado por elementos de oralidad implica pasar de uno que era fuertemente inquisitivo, en el que el juez tenía amplias posibilidades de decretar pruebas de oficio, a un proceso eminentemente dispositivo, que le permite a cada una de las partes presentar la prueba de los hechos en que fundan sus pretensiones, excepciones o defensas. Es obligación de cada parte probar los hechos que enuncia, so pena de ver afectados desfavorablemente sus intereses.

Es lógico que para que se dé la oralidad procesal es fundamental la reforma de la regulación de los medios de prueba, haciendo ciertos ajustes de menor identidad en algunos de ellos, pero en otros casos, tales ajustes implican un cambio total. Por ello, para Fierro (2006), los medios de prueba propios del proceso escrito y desconcentrado no pueden permanecer inalterados en el cambio hacia la oralidad y la concentración. Es en este sentido que una de las innovaciones que se dio al CGP y al CPA y de lo CA es buscar hacer compatible los dictados de la oralidad y el régimen probatorio, el cual debe ser abierto al cambio y a la modernización 
del sistema judicial desde el punto de vista formal y material, permitiendo abordar el problema de manera exhaustiva para que predomine el derecho.

Si se tiene en cuenta que la litis está centralizada en la audiencia, en una continuidad coordinada y rápida de encuentros personales y particulares, no en audiencias en grupo para debates orales ni de intercambio de escritos, cuanto más rápida sea la sustanciación, en una sola audiencia particular o en el menor número posible, una tras otra, mejor, porque el juez estará más cerca, tendrá más presente el caso y existirá menor riesgo de que se borren de su memoria las impresiones de las pruebas practicadas, de manera que la discusión oral y el fallo sean la conclusión inmediata a la sustanciación. De lo contrario, la no presencia real del juez en el proceso conlleva aplazamientos injustificados que detienen la sustanciación por meses.

La Corte Constitucional ha señalado que las reformas que el legislador ha implementado en el CGP y CPA y de lo CA son acordes la Constitución y con la protección de los derechos fundamentales de las partes, es así que en la sentencia C-124 de 2011 (Corte Constitucional, 2011, p. 5), la Corte expresa:

[...] un modelo procesal regido por la oralidad, de una nueva concepción del procedimiento civil, fundada en la preeminencia de la audiencia oral, en contraposición con el peso específico del proceso escrito, vigente hasta la reforma anotada. El legislador, en ese orden de ideas, hace uso de la amplia facultad de configuración legislativa a fin de establecer la oralidad como un instrumento de superación de la inveterada congestión de la jurisdicción civil en Colombia. Esta solución legislativa, que está dirigida a garantizar un proceso eficiente y, a su vez, respetuoso de los derechos fundamentales de las partes, en especial el debido proceso, se muestra prima facie compatible con la Constitución.

Para poder desarrollar elementos de oralidad en el proceso contencioso administrativo, los artículos 180, 181 y 182 de la Ley 1437 de 2011 establecen tres audiencias: una primera inicial, en la que el juez fija el litigio, decide las excepciones previas, sanea el proceso y decreta las pruebas pedidas por las partes; una segunda, para la práctica de pruebas; y una tercera, para presentar las alegaciones y proceder al juzgamiento. Es decir, la prueba será practicada y recaudada de forma oral (testimonios, declaración de parte, peritaje, etc.), con sujeción a los principios de inmediación, contradicción, publicidad y concentración y su controversia, por lo que se exige que se haga en presencia del juez. Pero es posible que el juez decida, 
dependiendo de que se necesite o no la práctica de pruebas o como consecuencia del debate de estas, en cuanto hace a la segunda y a la tercera audiencia prescindir de ellas, según el caso y, en cambio, adoptar la forma escrita para alegaciones para poder dictar sentencia. Por lo tanto, el manejo de la prueba depende de la conducción de las audiencias en el proceso y si a este debe dársele curso oral o escrito.

\section{La carga dinámica de la prueba}

Toda reforma que el legislador realice a la norma debe garantizar la protección de los derechos fundamentales reconocidos en un Estado social de derecho. Por lo tanto, al tenor de la Constitución Política Colombiana, artículo 1. ${ }^{\circ}$, el Estado debe responder por las condiciones sociales de existencia y por asegurar los derechos asistenciales; por ende, la naturaleza del Estado social de derecho es un papel activo de las autoridades y un compromiso permanente en la promoción de la justicia social.

Una de las bases para el direccionamiento del desarrollo de la organización del Estado es eliminar primordialmente la arbitrariedad por parte de este, situación que afecta a los ciudadanos (Ramírez, 1999). Esto implica que todo proceso judicial ha de estar definido no solo por las normas sustanciales y procesales de la legalidad ordinaria, sino también por las garantías fundamentales de acceso efectivo a la administración de justicia y del debido proceso. Como consecuencia de ello, las partes adquieren derechos subjetivos, obligaciones y cargas. Las obligaciones se encuentran impuestas por la ley, y la carga es la facultad que otorga el ordenamiento de ejecutar libremente determinado acto procesal y que por su inobservancia puede ser desfavorable, permitiendo con ello la aplicación de la carga de la prueba para las situaciones en que los sujetos procesales ingresan al proceso en condiciones de normalidad, con la posibilidad de variar las reglas de la carga de la prueba en presencia de situaciones de dificultad probatoria.

La carga de la prueba cada vez adquiere más importancia como un criterio o regla de decisión para el juez, que le indica cómo debe fallar ante las falencias probatorias; esta también tiene un papel orientador en la actividad probatoria de las partes, en el sentido de advertirles la necesidad de probar los hechos que alegan, evitando así consecuencias desfavorables que puedan traer su omisión.

Con la teoría de la carga dinámica de la prueba, se le da un instrumento poderosísimo al juez para que él reparta equitativamente la carga en los casos difíciles, 
en los que el sistema tradicional resulta insuficiente. Las cargas procesales se encuentran señaladas el artículo 167 del CGP, que a la letra dice:

Incumbe a las partes probar el supuesto de hecho de las normas que consagran el efecto jurídico que ellas persiguen. No obstante, cuando a una de las partes le resulte más fácil probar determinados hechos, corresponde a ella demostrarlos [...].

Y sobre las cargas procesales, la Corte Constitucional, en la sentencia C-279 de 2013 (Corte Constitucional, 2013, p. 3), indica:

[...] las cargas procesales son aquellas situaciones instituidas por la ley que comportan o demandan una conducta de realización facultativa, normalmente establecida en interés del propio sujeto y cuya omisión trae aparejadas para él consecuencias desfavorables, como la preclusión de una oportunidad o un derecho procesal e inclusive hasta la pérdida del derecho sustancial debatido en el proceso.

Tal es así, que los sujetos procesales pueden ingresar al proceso en condiciones de normalidad, dándose la posibilidad de variar las reglas de la carga de la prueba en presencia de situaciones de dificultad probatoria. La Corte Constitucional, en la sentencia T-835 de 2000 (Corte Constitucional, 2000) sobre el tema, indica que:

[...] la necesidad de distribuir la carga de la prueba en favor de la parte menos fuerte en la relación, de forma tal que esta únicamente se vea obligada a demostrar -con pruebas adicionales a su declaración consistente y de buena fe- aquellos hechos que esté en la posibilidad material de probar, correspondiéndole a la otra parte la prueba de las circunstancias que alegue en su favor para desvirtuar lo alegado en su contra.

Esa presunción surge como un importante recurso/instrumento para la modificación de la carga de la prueba en aquellos eventos de difícil acreditación de los hechos, con lo que, de paso, se contribuye con la protección de los derechos fundamentales como el de igualdad, al facilitar la prueba de su vulneración o amenaza. El compromiso que ha de tener el juez en aplicar la variación de las reglas de la carga de prueba en situaciones de dificultad probatoria se deben dar de acuerdo 
con lo establecido por la ley. El deseo del legislador es buscar, con la reforma, que el juez solamente sea el fallador y que la carga de conseguir las pruebas esté en cabeza de las partes.

Esto ocurre debido a que el CGP y el CPA y de lo CA, les asignan una amplia facultad a las partes, en lo referente a la constitución y aporte de las pruebas documentales y pruebas anticipadas en poder del demandante o del demandado en el momento de la presentación de la demanda o de su contestación, de manera que se alleguen a las audiencias debidamente recopiladas para el debate y sujetas a la inmediación y contradicción durante la respectiva audiencia que se adelante ante el juez.

En palabras del doctrinante Parra Quijano (2011), quien ha debatido sobre el tema de la prueba y a quién le compete probar, "el tema de la prueba está constituido por aquellos hechos que es necesario probar, por ser los supuestos de las normas jurídicas cuya aplicación se discute en un determinado proceso” (p. 135).

Por su parte, Rosenberg (2002) plantea:

Las reglas sobre la carga de la prueba [...] ayudan al juez a formarse un juicio, afirmativo o negativo, sobre la pretensión que se hace valer, no obstante, la incertidumbre con respecto a las circunstancias de hecho, porque le indican el modo de llegar a una decisión en semejante caso. La esencia y el valor de las normas sobre la carga de la prueba consisten en esta instrucción dada al juez acerca del contenido de la sentencia que debe pronunciar en un caso en que no puede comprobarse la verdad de una afirmación de hecho importante. La decisión debe dictarse en contra de la parte sobre la que recae la carga de la prueba con respecto a la afirmación de hecho no aclarada. (p. 7).

[...] cada parte tiene la carga de la afirmación y de la prueba con respecto a los presupuestos y las características o el estado de cosas relativos a las normas jurídicas que le son favorables, esto es, de las normas sin cuya aplicación la parte no puede tener éxito en el proceso. (p. 198).

Por ello, la carga de la prueba en lo referente a responsabilidad médica tiene fundamento constitucional en el debido proceso, manifestado en el derecho a la igualdad al momento de aportar las pruebas para confirmar o desvirtuar unos hechos que se debatirán en el litigio, pudiendo, por tanto, ser aportadas dentro del 
proceso, siempre que sean conducentes, pertinentes y útiles, para que no sufran el rechazo de manera motivada, sino que sean soportes jurídicos para la formación del convencimiento del Juez.

\section{Competencia de los procesos de responsabilidad médica}

Sin duda alguna, uno de los grandes cambios del Código General del Proceso es la modificación del numeral 4 del artículo 2 de la Ley 712 de 2001, referente a la competencia, que después de muchas discusiones en casos laborales y de seguridad social fue atribuida al juez laboral, como consecuencia de la interpretación jurisprudencial realizada a dicho artículo. La disconformidad en ese aspecto deviene de la lectura que se le da a la norma contenida en el Código Procesal del Trabajo, con la modificación que introdujo la Ley 712 de 2001 en el artículo 2 en cuanto a la competencia, en el que señala:

La Jurisdicción Ordinaria, en sus especialidades, laboral y de seguridad social conoce de:

$[\ldots]$

4. Las controversias referentes al sistema de seguridad social integral que se susciten entre los afiliados, beneficiarios o usuarios, los empleadores y las entidades administradoras o prestadoras, cualquiera que sea la naturaleza de la relación jurídica y de los actos jurídicos que se controviertan $[\ldots]$.

Si bien esta disposición permite interpretaciones, conlleva que asuntos sobre los mismos hechos puedan ser conocidos por jueces diferentes, sin que esto implique la negación del servicio o la imposibilidad de acceder a este, toda vez que las normas procesales regulan esas eventualidades en las figuras de nulidades por falta de competencia funcional y conflicto de competencia.

Esta situación generaba incertidumbre al momento de ejercer el derecho de acción ante la administración de justicia por hechos relacionados con la responsabilidad médica y determinar la jurisdicción llamada a conocer de tales controversias, escenario que fue resuelto por el legislador al regular la competencia en la Ley 1564 de 2012 (CGP), en la que señala de manera expresa el conocimiento de los 
referidos litigios a los jueces civiles, de acuerdo con la cuantía, así como lo indica en el artículo 17, que a la letra reza:

Los jueces civiles municipales conocen en única instancia: 1 . De los procesos contenciosos de mínima cuantía, incluso los originados en relaciones de naturaleza agraria, salvo los que correspondan a la Jurisdicción Contencioso Administrativa. También conocerán de los procesos contenciosos de mínima cuantía por responsabilidad médica, de cualquier naturaleza y origen, sin consideración a las partes, salvo los que correspondan a la Jurisdicción Contencioso Administrativa [...].

En el artículo 18, en lo referente a la competencia de los jueces civiles municipales, indica que:

Los jueces civiles municipales conocen en primera instancia: 1. De los procesos contenciosos de menor cuantía, incluso los originados en relaciones de naturaleza agraria o de responsabilidad médica, salvo los que correspondan a la jurisdicción contencioso administrativa.

También conocerán de los procesos contenciosos de menor cuantía por responsabilidad médica, de cualquier naturaleza y origen, sin consideración a las partes, salvo los que correspondan a la Jurisdicción Contencioso Administrativa [...].

Por su parte, el artículo 20 indica la competencia de los jueces civiles del circuito en primera instancia, que conocerán asuntos como:

1. De los contenciosos de mayor cuantía, incluso los originados en relaciones de naturaleza agraria, salvo los que le correspondan a la Jurisdicción Contencioso Administrativa.

También conocerán de los procesos contenciosos de mayor cuantía por responsabilidad médica, de cualquier naturaleza y origen, sin consideración a las partes, salvo los que correspondan a la Jurisdicción Contencioso Administrativa [...].

De igual manera, el artículo 625 de la misma ley expresa que aquellos procesos de los que venían conociendo los jueces laborales deben ser remitidos en el estado 
en que se encuentren a los jueces civiles, en lo referente al tránsito legislativo, y en este aspecto indica:

Los procesos en curso al entrar a regir este código se someterán a las siguientes reglas de tránsito de legislación:

$[\ldots]$

Sin embargo, los procesos de responsabilidad médica que actualmente tramitan los jueces laborales serán remitidos a los jueces civiles competentes, en el estado en que se encuentren.

Así mismo, en el artículo 622, que modificó el numeral 4 del artículo 2 del Código del Trabajo y de la Seguridad Social, en el ámbito de la competencia de los jueces laborales en los asuntos de seguridad social, precisa:

Las controversias relativas a la prestación de los servicios de la seguridad social que se susciten entre los afiliados, beneficiarios o usuarios, los empleadores y las entidades administradoras o prestadoras, salvo los de responsabilidad médica y los relacionados con contratos.

En relación con este tema, el Consejo de Estado expone lo siguiente: (con lo cual se define y concluye la controversia de cómo, cuándo y en qué estado del proceso se pueden pasar los procesos de responsabilidad médica del juez laboral al juez civil) (Consejo de Estado. Sala de lo Contencioso Administrativo. Sección Tercera, 1992).

[...] aceptar que una misma causa de responsabilidad médica se pueda ver sometida en distintos momentos ante jueces que forman parte de ramos diferentes de la justicia ordinaria. También es verdad que el derecho sustancial y procesal que informa la administración de justicia en cada ramo presenta diferencias de principios o de orientaciones filosóficas. No obstante, esto no es suficiente para sostener que se hubiese desconocido la Constitución con la variación de competencia de procesos de responsabilidad médica en curso. Todos los jueces de la República, en la medida en que son jueces de tutela (CP, art. 86) y en cuanto deben observar ante todo la Constitución como "norma de normas" (CP, art. 4), tienen un horizonte y 
un límite común que está conformado por los derechos fundamentales. Mientras la variación de competencias, incluso de procesos en curso, implique trasladar los procesos pendientes a un ramo de la justicia ordinaria que respete los parámetros antes mencionados y, sobre todo, mientras el funcionamiento de dicho ramo no se sustraiga del marco más amplio de los principios de la Constitución, la reforma debe juzgarse constitucional. Enmarcar un proceso en curso en uno u otro ramo de la justicia ordinaria no es entonces contrario por principio a la Carta, si en uno y otro se respetan las disposiciones de esta última. Y eso es lo que ocurre, en abstracto, con los ramos civil y laboral de la justicia ordinaria.

\section{Prueba pericial: del dictamen judicial al dictamen de parte}

Hoy en día, los ciudadanos son más conscientes de los derechos que les asisten, esto debido a que los medios de comunicación los han difundido, más cuando se trata del actuar del servicio médico y de las entidades prestadoras de salud, en temas relacionados con la salud o con el aspecto estético. Así mismo, cuando se presenta falla del servicio, estas entidades son visitadas por entes judiciales con el fin de verificar su prestación y establecer si este ha sido o no prestado de acuerdo con los protocolos ético-médicos. Por este último motivo, se generan demandas, bien sea de carácter ético, disciplinario, penal, civil o incluso contencioso-administrativo, en contra de los médicos y de las entidades a las cuales se encuentran adscritos, para establecer si el galeno es o no responsable de una mala praxis, colocando en tela de juicio el ejercicio de la profesión.

Ante esta circunstancia, un papel fundamental dentro del acervo probatorio es, sin lugar a dudas, la prueba pericial, que se realiza por medio de los avances científicos y tecnológicos que una persona instruida y de conocimientos especiales en la materia hace con relación al tema que va a controvertir y esclarecer una prueba (Parra, 2011), siendo, por tanto, el medio de convicción determinante aportado al proceso porque, de acuerdo con la opinión del experto, se logra la resolución del litigio, y hoy en día se hacen necesarios en los procesos judiciales.

Florián (citado por Solórzano, s. f.) señala que "la peritación es el medio particularmente empleado para transmitir y aportar al proceso nociones técnicas y objetos de prueba, para cuya determinación y adquisición se requieren conocimientos especiales y capacidad técnica”. Precisamente, porque la prueba pericial es de gran relevancia en los procesos de reparación directa con el fin de comprobar si existió una falla 
en el servicio, especialmente en los de responsabilidad médica, y poder valorar la conducta de un médico estableciendo si este actuó conforme a lo que indica la ley de ética médica, o la lexartis, por eso necesariamente se requiere de un experto que en calidad de perito determine si el médico actuó o no conforme a lo que ordena la ciencia médica, de allí que esencialmente se debe señalar que en procesos en los cuales se juzgue a un profesional médico sin que exista perito médico, difícilmente se podrá concluir si este es o no responsable. Por tal motivo, no se puede pasar por alto su incursión en la oralidad, porque aporta no solo eficacia al proceso, sino también credibilidad y seguridad jurídica a las partes en el momento en que el juez emita el fallo, independientemente de a quién favorezca.

En ese sentido la Corte Suprema de Justicia, Sala de Casación Civil (1990 p. 16), señala en uno de sus primeros fallos en relación a los casos de responsabilidad médica que la prueba pericial resulta fundamental. Específicamente esa corporación indica:

El dictamen técnico de expertos médicos es indudablemente el medio probatorio que ofrece mayor poder de convicción cuando se trata de establecer las causas que produjeron el deceso de una persona por la actividad de otras. Acerca de este mayor valor demostrativo de esa prueba, ha dicho esta Corporación: es verdad que en muchos casos las causas determinantes de una muerte no caen bajo el dominio de los sentidos de las personas que puedan presentarla, y que en otros casos tales causas son ajenas al conocimiento general de las gentes. Entonces, la prudencia indica recurrir a los científicos para que estos, mediante el examen de las lesiones y demás fenómenos que presenta el cadáver, expliquen las causas que determinaron la muerte. En la mayoría de las veces, la prueba pericial es la más apropiada para establecer la causa de la muerte de una persona, medio probatorio técnico que esta sala ha exigido en algunos casos.

Como se puede observar, el mundo médico es tan especializado, que un juez difícilmente podrá llegar a conocer la realidad de lo acontecido, cuáles fueron los hechos que se presentaron y las causas que llevaron a que se produjese la muerte de un paciente o daños en su salud si no cuenta con la prueba pericial. No es solamente que se determine la causa de la muerte o de las lesiones, sino que se establezca si existe relación o no con el acto médico y, en caso de tener relación con este, que sea inherente a él por haber creado un riesgo jurídicamente desaprobado, es decir, por haber violado un deber de cuidado que le era exigible. 
La prueba pericial representa un valor probatorio que permitirá condenar o absolver la responsabilidad médica atribuida a un galeno o a una entidad prestadora del servicio de salud por falla del servicio o por mala praxis (Corte Constitucional, 2012, p. 1). Por consiguiente, si la prueba pericial no ha sido decretada por el juez ni controvertida dentro del proceso, carece de mérito probatorio y no puede ser valorada judicialmente, porque no es una prueba legalmente practicada.

Con el dinamismo de la carga de la prueba es claro precisar que esta podrá presentarse a solicitud de parte o de oficio por el juez, siendo sobresaliente la prueba pericial que permitirá demostrar la existencia de los tres elementos de la responsabilidad, como lo son el daño, la falla del servicio y el nexo de causal, los cuales son concluyentes para que el juez pueda fallar en derecho. En un proceso de responsabilidad médica, el dictamen médico sirve para demostrar la relación de casualidad y la culpa si se logra probar esa conexidad, y es el perito médico quien señala si esa acción u omisión fue negligente y si fue la causa que originó el perjuicio sufrido por el reclamante, a quien, por regla general, le incumbe demostrar, además del daño, los dos elementos de responsabilidad (la culpa y la relación de causalidad), que conforman la valoración que determina la relación de causalidad.

Por otro lado, con la reforma al CCA por medio de la Ley 1437 de 2011, en el artículo 218, el legislador introduce como novedad el dictamen de parte, pero conservando la figura del perito judicial, generando un sistema dual o mixto; pero por tratarse de un sistema oral de juzgamiento, lo conveniente es un dictamen de parte, ya que lo que se quiere es la reducción de trámites. De igual manera, la reforma no regula el número de peritos ni de dictámenes, como tampoco elimina la fijación de gastos y honorarios, sino que regula el pago de honorarios al perito de parte cuando la contraparte solicite complementación.

Dispone, además, la tacha del perito de parte que se debe interponer en la audiencia siguiente de la aportación del dictamen, sin determinar qué debe hacer el juez cuando ella prospere. Al respecto, Bermúdez (2012) señala:

Este es un trámite innecesario y que el legislador podría obviar si se advierte que la imparcialidad debe exigirse del dictamen y no del perito [...]. El perito de parte, por el contario, es parcial porque concurre al proceso contratado por una parte y con el objeto de demostrar una afirmación que le interesa a dicha parte (p. 26). 
Así mismo, la norma prevé que los peritos de parte deben asistir a la audiencia, en la cual pueden ser interrogados por las partes, remitiendo a la regulación del CGP (Ley 1564 de 2012).

Bermúdez (2012) indica que con el perito judicial no se otorga a las partes el derecho a probar sus afirmaciones; que en dicho sistema equivocadamente se le impone al juez la obligación de resolver el problema técnico o científico, auxiliado por un perito que él mismo designa, lo que lo lleva a emitir opiniones sobre temas que no conoce. Con el perito de parte, la labor del juez está dirigida a determinar si la parte cumplió con la carga de convencerlo de que su afirmación está adecuadamente sustentada desde el punto de vista técnico, por medio de una discusión dialéctica que le permitirá apreciar, en todo su contexto y con todos sus extremos, la cuestión materia de la discusión (p. 31).

En materia de la prueba pericial, el propósito principal del Código General del Proceso (CGP) es el de trasladar a las partes la responsabilidad de acompañar la experticia a la demanda o la contestación cuando se desee probar hechos que requieran conocimientos de los que carezca el juez. En efecto, el artículo 227 del CGP prevé que "la parte que pretenda valerse de un dictamen pericial deberá aportarlo en la respectiva oportunidad para pedir pruebas". Agrega la disposición, inclusive, que, si la parte no cuenta con tiempo suficiente para aportar el dictamen, deberá al menos anunciarlo y posteriormente entregarlo dentro de los diez días siguientes para que el juez notifique a las partes y a terceros, con el fin de que colaboren con su práctica. Dicho dictamen deberá ser emitido por una institución o o por un profesional especializado.

De acuerdo con lo señalado en el Código General del Proceso, salvo cuando el juez decrete un dictamen pericial de oficio (art. 230), ya no se podrá solicitar en la demanda o en su contestación que se realice una experticia en el curso del proceso, cesando la opción que se tenía de solicitar la práctica de un dictamen pericial por medio de un experto nombrado de la lista de auxiliares de la justicia o acompañar uno rendido por un especialista en el tema por tratar (art. 229, numeral 2). Surge entonces la duda de si accionante y accionado están en capacidad de sufragar los costos que requiere la realización de la pericia, que tendrán que aportar obligatoriamente con la demanda o la contestación. Por ello, ha de presumirse que todas las personas tendrán los recursos necesarios o contarán con expertos suficientes para solicitar la realización de una experticia para así cumplir el requisito de aportarla como lo dicta el artículo 227 del CGP. 
Las personas que no cuenten con los recursos para sufragar los costos periciales pueden hacer uso del amparo de pobreza señalado en el artículo 151 de la ley en mención, aún antes de la presentación de la demanda, lo que podrá hacer posible que al perito a quien se le solicite realizar el trabajo se le remunere no por quien lo contrató, sino por su contraparte, como lo dispone el artículo 157 del CGP.

A pesar de que el artículo 230 del CGP da la posibilidad de que el dictamen pueda ser decretado de oficio por el juez, este solo podrá practicarse en el periodo probatorio, es decir, con posterioridad a la presentación de la demanda o de la contestación, momentos procesales en los que ha de acompañarse obligatoriamente el trabajo pericial, lo cual no es la solución a las dificultades a las que puede enfrentarse una de las partes cuando está en la obligación de aportar desde el inicio la pericia que pretende hacer valer como prueba.

Tampoco el problema planteado se resuelve con el artículo 189 del CGP, pues, aunque esta disposición autoriza la prueba extraprocesal de inspección judicial con peritaciones, no permite el decreto ni la práctica de una pericia anticipada al proceso. Adicionalmente, para quien no tiene recursos económicos, el camino del amparo de pobreza tampoco es viable en la práctica de una prueba pericial extraprocesal por la sencilla razón de que no habría contraparte obligada a pagar las expensas de esa experticia.

Es importante resaltar la reforma que se le hizo al Código Contencioso Administrativo, hoy Ley 1437 de 2011, en lo referente al tema del aporte del dictamen pericial, el cual se hace necesario para probar un derecho o para oponerse a las pretensiones de la demanda, en el momento de su presentación o de la contestación, según como lo establecen los artículos 162 (numeral 5) y 175 (numeral 5), en los que se indica que, llegado el caso en que el demandado en la contestación de la demanda declare que va a presentar dictamen pericial para demostrar su derecho, se le amplíe el término para contestarla hasta por treinta (30) días más, contados a partir del vencimiento del término inicial, con el fin de que cuente con un plazo adecuado para su elaboración, teniendo en cuenta la complejidad del asunto materia de la controversia y los trámites que deba adelantar para tal efecto. Sin embargo, se predice que, en caso de que el demandante se valga de la ampliación del término para contestar y no aporte a esta el dictamen pericial, se entenderá que fue presentada en forma extemporánea.

Dentro de este contexto, el artículo 218 (Ibíd.) se refiere a la prueba pericial, y al respecto expresa que "la prueba pericial se regirá por las normas del Código de 
Procedimiento Civil, salvo en lo que de manera expresa se disponga en este Código sobre la materia”. Es así como se contempla un tratamiento especial de algunos aspectos de la prueba pericial para que un medio de convicción tan importante en el proceso contencioso, y de por sí complejo por su naturaleza técnica, cuente con unas reglas coherentes en cuanto a su oportunidad, debate y contradicción, reglas señaladas en los artículos 212, 219 y 220 (Ibíd.), dentro del marco de un sistema mixto de proceso oral y escrito.

De ahí que es de obligatoriedad de toda entidad pública demandada o particular que ejerza funciones administrativas como demandado, allegar, durante el término que señala la ley para dar respuesta a la demanda, las pruebas documentales en su poder que puedan interesar al proceso, las cuales, como se indica en el parágrafo primero del artículo 175 de la Ley 1437 de 2011, son:

a. El expediente administrativo que contenga los antecedentes de la actuación objeto del proceso ${ }^{10}$.

b. En los procesos de responsabilidad médica, copia íntegra y auténtica de la historia clínica pertinente, a la cual se agregará su transcripción completa y clara, debidamente certificada y firmada por el médico que haga la transcripción, con lo cual, este tipo de procesos contará con una prueba vital que se encuentra en la esfera de producción del demandado y que casi todas las veces es de difícil consecución para el demandante.

Estas disposiciones son, además, el desarrollo del principio de la economía procesal, por lo tanto, con el fin de forzar a su cumplimiento, la norma establece que la inobservancia de estos deberes constituye falta disciplinaria gravísima del funcionario encargado del asunto.

Del análisis realizado a la normatividad y a la jurisprudencia en lo referente a la prueba pericial, la carga dinámica de la prueba y la oralidad, en lo que respecta a la responsabilidad médica frente a la reforma del Código de Procedimiento Civil y al Código Contencioso Administrativo, se puede evidenciar que, al haberse implementado la oralidad en los procesos de responsabilidad médica, se logra el cumplimiento de los diferentes principios constitucionales, como son la celeridad, la inmediación y la concentración. Esto permite una actuación efectiva de los intereses individuales y sociales que el proceso debe tutelar, asegurando, de paso,

${ }^{10}$ Nota: Es de recordar que en el Código anterior (art. 207 n. ${ }^{\circ}$ 6), dichos antecedentes administrativos se pedían por el juez en el auto admisorio de la demanda. 
una justicia más eficaz, expedita y, sobre todo, que afiance los sentimientos de confianza de los colombianos. Esta justicia resulta garantista y asegura en máximo grado la inmediación, es decir, un contacto directo y simultáneo de los sujetos procesales con los medios de prueba en que deben basarse la discusión plena de las partes y la decisión definitiva del juzgador, lo cual favorece las actuaciones procesales al abordar el problema integral para que prevalezca el derecho. $\mathrm{Y}$ al dividirse en distintas etapas procesales, permite la publicidad real y logra de esta manera que se dé un proceso ágil y una solución con avances sustanciales en los numerosos problemas de la justicia civil.

En cuanto a la carga dinámica de la prueba, el legislador tuvo en cuenta las garantías fundamentales de acceso efectivo a la administración de justicia y del debido proceso, consintiendo que los sujetos procesales ingresen al proceso en condiciones de normalidad, con la posibilidad de variar las reglas de la carga de la prueba en presencia de situaciones de dificultad probatoria. Así mismo, permite orientar a las partes en el sentido de advertirles la necesidad de probar los hechos que alegan, evitando así las consecuencias desfavorables que pueda traer su omisión. Con la teoría de la carga dinámica de la prueba, se le da un instrumento poderosísimo al juez para que él reparta equitativamente la carga en los casos difíciles en los que el sistema tradicional resulta insuficiente, indicándole a su vez cómo debe fallar.

La prueba pericial en los temas de responsabilidad médica es fundamental para que la conducta de un médico pueda ser valorada y así establecer si este actuó conforme a lo que establece la ley de ética médica, o la lexartis, razón por la cual se requiere necesariamente de un experto que en la calidad de perito compruebe si el médico actuó o no conforme a lo que ordena la ciencia médica, de allí que inevitablemente se debe señalar que en procesos en los que se juzgue a un profesional médico sin que exista perito médico, difícilmente se podrá concluir si este es o no responsable.

Con el dinamismo de la carga de la prueba, es claro precisar que esta podrá ser a solicitud de parte o de oficio por el juez, resultando relevante en cuanto a que la prueba pericial permitirá demostrar la existencia de los tres elementos de la responsabilidad: el daño, la falla del servicio y el nexo de causalidad, los cuales son determinantes para que el juez pueda fallar en derecho.

Con la reforma al CCA por medio de la Ley 1437 de 2011, en el artículo 218, el legislador introduce como novedad el dictamen de parte, pero conservando la figura del perito judicial, generando un sistema dual o mixto; y por trararse de un 
sistema oral de juzgamiento, lo conveniente es el dictamen de parte, ya que lo que se quiere es la reducción de trámites. Así mismo, la reforma no regula el número de peritos ni de dictámenes, tampoco elimina la fijación de gastos y honorarios, sino que regula el pago de honorarios al perito de parte cuando la contraparte solicite complementación. De otra parte, dispone la tacha del perito de parte, que se debe interponer en la audiencia siguiente de la aportación del dictamen, pero no se determina qué debe hacer el juez cuando ella prospere.

\section{Conclusiones}

La oralidad y la escritura no son rasgos característicos absolutos de ninguna época o modelo jurídico de la sociedad (no son verdaderos principios, ni siquiera reglas técnicas absolutas). La oralidad y la escritura son maneras distintas de abordar una de las problemáticas del proceso, prevaleciendo una u otra en los últimos siglos. Actualmente se pasa por uno de sus momentos históricos de mayor dinamismo y transformación, en el que vienen emergiendo nuevos modos de ver y asumir la realidad y abordar los problemas, lo cual se refleja según como el legislador lo señale en la ley, ya se trate de una u otra etapa del proceso, de una u otra rama del derecho, de uno u otro criterio doctrinal dominante (mera ideología) o según los medios y recursos de que se disponga.

No existe ni puede existir procedimiento totalmente oral, porque sería contraproducente para la seguridad jurídica. Hay actos procesales que necesariamente deben ser escritos o al menos hacerse constar en actas, como lo son La acusación y la sentencia.

El procedimiento oral se fundamenta en que la producción de las pruebas y los alegatos de las partes se presentan ante el juzgador, quien decidirá la causa; y con la nueva dinámica de la oralidad presente en el juicio oral en la Reforma Procesal Colombiana, se evidencia con claridad la necesidad de propiciar un encuentro entre justicia y lenguaje. Esto implica establecer una mejor comprensión sobre las diversas dimensiones cognitivas, gramaticales, éticas, axiológicas, etc., que están relacionadas con la oralidad.

En tal sentido, dentro del sistema que se implanta, resulta determinante el manejo del lenguaje jurídico, que se caracteriza no solo por un fuerte desarrollo tecnológico, sino por el manejo adecuado de la conducta del profesional, en la que juega papel importante el conocimiento del derecho sustancial y procesal. A su vez, 
en el desarrollo del proceso participa un grupo de personas no profesionalizadas en temas jurídicos, como son los demandantes, los demandados, los testigos, entre otros, que desconocen el lenguaje técnico empleado en dicho contexto procesal. De manera que es de difícil comprensión para los actores "no especializados", quienes no son dueños de la situación, en virtud de que no les será fácil entender los rituales procesales y, en muchas ocasiones, lo que se desarrolla o ventila en la audiencia.

Con la implementación de la oralidad, serán muchas las vicisitudes que se deberán superar, para lo cual se requiere capacitar a los jueces y abogados sobre lo que es realmente el procedimiento oral, para que, de esta manera, los resultados se acerquen a las metas propuestas en materia de eficacia, celeridad y descongestión. Es importante resaltar que la oralidad rescata el carácter lógico del proceso, permitiendo además una participación amplia de los involucrados y obligando a los jueces y abogados a un estudio serio de cada causa y a posiciones imparciales.

En cuanto a la prueba pericial, resulta ser imprescindible. Si bien es cierto que los tribunales están conformados por profesionales, esto no quiere decir que puedan tener conocimientos especializados en todos los campos y, al igual que en cualquier otro proceso, requieren de la presencia de la prueba pericial para fundamentar su fallo, resultando de gran relevancia los peritazgos emitidos por el Instituto de $\mathrm{Me}$ dicina Legal, así como también los de los miembros de las comunidades científicas.

A pesar de que el Código de Ética Médica presenta vacíos, estos se pueden suplir con la normatividad, tanto como del Código de Procedimiento Penal, el Código de Procedimiento Civil o el Código Contencioso Administrativo, para efectos de determinar cómo se pueden practicar y valorar las pruebas, ya que se presenta la ventaja de que el perito puede acudir ante la autoridad para ser interrogado y, en el desarrollo de esta, incorpore su informe pericial en aras de que sean los magistrados los que puedan valorar por interrogatorio directo el correspondiente peritazgo.

La relación entre una obligación y un derecho genera una responsabilidad en la que la primera tiene que ver con la persona que presta un servicio o cumple un mandato y el segundo recae no solo en quien puede hacerlo valer por su condición personal como mandante, sino también en quien se encuentra en una circunstancia específica y requiere ejercerlo. Es debatible que el médico, como cualquier otro profesional, ha de ser responsable de sus negligencias, y con mayor sentido de su mala práctica, en la que las consecuencias legales bien las enmarca la legislación cuando dice: "Que quien por acción u omisión causa daño a otro, interviniendo la culpa o negligencia, está obligado a reparar el daño causado”. 
Si bien es cierto que el error es perfectamente lógico en cualquier actividad humana, y la medicina no está exenta de este, lo es también que el derecho a equivocarse es una responsabilidad que asume el individuo. Se entiende que hay una diferencia muy grande entre el error y la mala práctica médica, pero que esta se escude en que la medicina no es una ciencia exacta, no es aceptable, porque se presume que quien la practica es un profesional a quien se le exige una experiencia y una categoría, máxime cuando lo que se debe proteger es nada menos que la vida de un ser humano. También debe entenderse que el error, pese a ser posible, dependiendo de su gravedad puede eximir de responsabilidad ética, penal o disciplinaria a quien lo cometa, sin que ello signifique que la persona que lo padece este obligado a soportarlo sin contar con algún medio de reparación.

La medicina conlleva una enorme responsabilidad que resulta de las características que abarcan su práctica, por ello existe un concepto básico, y es que todo procedimiento, ya sea terapéutico, quirúrgico o de diagnóstico, tiene asociado un riesgo para el paciente, representado en las acciones del médico que eventualmente pueden ocasionar algún daño o secuela psíquica o física. Este riesgo, que es soportado por el enfermo, debe ser asumido por el galeno o practicante y obviamente tiene unas implicaciones legales, dado que el afectado puede recurrir a la justicia en caso de sentirse perjudicado. Incluso, tratándose de responsabilidad de personas de derecho público, los daños causados al paciente que se derivan de un correcto proceder, el cual observa todas las reglas de la práctica y que adopta las respectivas medidas de prevención y paliación, también es reparable, esto en virtud del régimen de responsabilidad objetiva. Ejemplos de lo anterior son las denominadas infecciones intrahospitalarias, las cuales permanecen en el ambiente clínico y cuya presencia no obedece a alguna acción u omisión del personal médico. En estos casos, el Consejo de Estado ha considerado que, pese a que el origen del daño no es imputable al centro médico o a su personal, el paciente no está en el deber jurídico de soportar el daño, por lo que debe ser reparado; en ese sentido, la misma corporación ha conminado a la red pública hospitalaria para que cree un fondo que permita soportar las contingencias derivadas de estas indemnizaciones.

Con frecuencia, el médico se enfrenta al dilema de escoger entre dos o más soluciones. Se plantea, por una parte, qué es lo que debe hacer por el bienestar del paciente, dentro del criterio científico, y cuál de las probables acciones es la más favorable o menos dañina para aquel, decisión que toma de acuerdo con los riesgos inherentes al acto médico y obedeciendo siempre a los principios de respeto a la 
vida, a la integridad humana, a la preservación de la salud, entre otros. A pesar de esto, todo profesional de la medicina está sujeto a situaciones que conllevan acciones judiciales, bien sea en una demanda civil, administrativa o acusación penal por una supuesta mala praxis médica, siendo posible, en criterio personal, catalogar el acto médico como una actividad peligrosa.

\section{Referencias}

Bejarano, R. (s. f.). El drama pericial. Ámbito Jurídico [en línea]. Recuperado de goo.gl/GsxSUA Bermúdez, M. (2012). Del dictamen judicial al dictamen departe. Bogotá: NET Educativa Editorial. Congreso de la República de Colombia. (5 de diciembre de 2001). Ley 712 de 2001. Por la cual se reforma el Código Procesal del Trabajo. Diario Oficial 44.640 del 8 de diciembre de 2001. Recuperado de goo.g1/8Eg $3 \mathrm{~Pb}$

Constitución Política de Colombia [Const]. Julio 7 de 1991 (Colombia).

Congreso de la República de Colombia. (18 de enero de 2011). Ley 1437 de 2011. Por la cual se expide el Código de Procedimiento Administrativo y de lo Contencioso Administrativo. Diario Oficial 47.956 del 18 de enero de 2011. Recuperado de goo.g1/18kNVq

Congreso de la República de Colombia. (06 de agosto de 1970). Decreto 1400 de 1970. Por la cual se expide el Código de Procedimiento Civil. Diario Oficial No. 33.150 de 21 de septiembre de 1970. Recuperado de http://www.secretariasenado.gov.co/senado/ basedoc/codigo_procedimiento_civil.html

Congreso de la República de Colombia. (02 de enero de 1984). Decreto 01 de 1984. Por la cual se expide el Código Contencioso Administrativo. Diario Oficial No. 36.439, del 10 de enero de 1984. Recuperado de http://www.secretariasenado.gov.co/senado/ basedoc/codigo_contencioso_administrativo.html

Congreso de la República de Colombia. (24 de Julio de 2000). Ley 599 de 2000. Por la cual se expide el Código Penal. Diario Oficial No. 44.097 de 24 de julio del 2000. Recuperado de http://www.secretariasenado.gov.co/senado/basedoc/ley_0599_2000.html

Congreso de la República de Colombia. (18 de Febrero de 1981). Ley 23 de 1981. Por la cual se expide el Código de Ética Medica. Diario Oficial No. 35.711 de 27 de febrero de 1981. Recuperado de http://www.archivogeneral.gov.co/sites/all/themes/nevia/PDF/ Transparencia/LEY_23_DE_1981.pdf

Congreso de la República de Colombia. (12 de julio de 2012). Ley 1564 de 2012. Por medio de la cual se expide el Código General del Proceso y se dictan otras disposiciones. Diario Oficial 48489 del 12 de julio de 2012. Recuperado de goo.gl/KMV76B 
Correa, C. A. (2015). La historia clínica. Aspectos jurídicos y dilemas en el derecho español y colombiano. Revista Via Inveniendi et Iudicandi, 10(2), 125-144. Recuperado de goo. $\mathrm{g} 1 / \mathrm{ckMWhr}$

Echeverri, Á. (2011). La reforma judicial y consolidación de la democracia. Revista IUSTA, 1(34), 45-53. DOI: 10.15332/s1900-0448.2011.0034.03

Fierro, H. (2006). Manual de derecho procesal penal. Sistema acusatorio

y juicio oral y público. Bogotá. Leyer. 2005.

González, O. (2014). La Corte Constitucional como agente del campo jurídico colombiano: la omisión legislativa de principios constitucionales. Revista IUSTA, 2(41), 123-137. DOI: $10.15332 / \mathrm{s} 1900-0448.2014 .0041 .01$

Namén, Á. (2011). Régimen probatorio, nulidades e incidentes en el Nuevo Código de Procedimiento Administrativo y de lo Contencioso Administrativo. Recuperado de

http://studylib.es/doc/94867/conferencia-pruebas-incidentes-y-nulidades-e-en-el-nuevo-...

Parra, J. (2004). Manual de derecho probatorio. 14a ed. Bogotá: Librería Ediciones del Profesional Ltda.

. (2012). Reflexiones sobre algunos aspectos importantes del Código General del Proceso. En U. Libre (Ed.), XXIII Congreso Colombiano de Derecho Procesal (pp. 1732). Bogotá: Universidad Libre. Recuperado de http://www.cej.org.co/observatoriocgp/ index.php/documentos-de-interes.html

Quintero, A. (2015). El recurso de apelación en el Código General del Proceso: un desatino para la justicia colombiana. Revista Via Inveniendi et Iudicandi, 10(2),101-124. Recuperado de goo.g1/jldPMP

Ramírez, J. (1999). Principios constitucionales del derecho procesal. Medellín: Señal Editora.

Rojas, M. (2015). Responsabilidad civil médica. La valoración de la prueba. La casualidad en el acto médico (3. ${ }^{a}$ ed.). Bogotá: Librería Jurídica Sánchez R. Ltda.

Rosenberg, L. (2002). La carga de la prueba. Montevideo. Editorial B de F.

Solórzano, G. C. (s. f.). La prueba pericial y su importancia dentro de los procesos por mala práctica médica. Recuperado de

http://temvalle.org/seminarios.php

\section{Jurisprudencia}

Consejo de Estado. Sala de lo Contencioso Administrativo. Sección Tercera. (24 de agosto de 1992). Sentencia 6754. C. P. Carlos Betancur Jaramillo. Recuperado de http:// consejo-estado.vlex.com.co/vid/-355912930

Corte Constitucional. (2000). Sentencia T-835/00. M. P. Alejandro Martínez. 
Corte Constitucional. (2012). Sentencia T-274/12. M. P. Juan Carlos Henao Pérez.

Corte Constitucional. (2013). Sentencia C-279/13. M. P. Jorge Ignacio Pretelt.

Corte Constitucional. (2005). Sentencia C-591/05. M. P. Clara Inés Vargas.

Corte Constitucional. (2008). Sentencia T-760/08. M. P. Manuel José Cepeda.

Corte Constitucional. (2011). Sentencia C-124/11. M. P. Luis Ernesto Vargas.

Corte Suprema de Justicia. Sala de Casación Civil. (8 de mayo de 1990). Sentencias del 8 de mayo de 1990. M. P. Eduardo García Sarmiento. 